\title{
Methods for evaluating innovative surgery: a nested ideal phase 2 study within an external randomised pilot (the ROMIO trial)
}

\author{
Jane Blazeby ${ }^{1,2^{*}}$, Richard Berrisford ${ }^{3}$, Dan Titcomb ${ }^{1}$, Andrew Hollowood $^{1}$, Grant Sanders ${ }^{3}$, Christopher Streets ${ }^{1}$, \\ Tim Wheatley ${ }^{3}$, Kerry Avery ${ }^{2}$, George Hanna ${ }^{4}$, Chris Metcalfe ${ }^{2}$, Paul Barham ${ }^{1}$
}

From 3rd International Clinical Trials Methodology Conference

Glasgow, UK. 16-17 November 2015

\section{Introduction}

Pragmatic surgical RCTs are needed but it is unclear how to design studies with evolving innovative interventions. The aim of this paper was to describe how a pilot RCT comparing two standard techniques incorporated an additional randomised group with a nested IDEAL (Idea, Development, Evaluation, Assessment and Long-term evaluation of innovative surgery) Phase $2 b$ evaluation of an evolving technique to inform main trial design.

\section{Methods}

In centre one (three surgeons), patients were randomised to two types of standard surgery. In centre two (six surgeons), patients were also randomised to a third group including an evolving new surgical technique. Surgical protocols for standard techniques were agreed and monitored, whereas the evolving technique's protocol was flexible to allow innovations, yet outcomes and processes to be monitored. Patients were blinded to intervention received using large wound bandages.

\section{Results}

Over 50 centre months, 237 patients were assessed for eligibility, 154 (65\%) were eligible and 120 (78\%) participated. Most $(86 \%)$ received their randomised allocation. Patients were successfully blinded whilst assessing pain during the first week. In the evolving technique, surgery changed after three months, with a modified approach and anastomosis. This further evolved but did not stabilise during the pilot study. The main trial has been

${ }^{1}$ University Hospitals Bristol NHS Foundation Trust, Bristol, UK

Full list of author information is available at the end of the article designed with a two-group comparison and the nested IDEAL study will continue in selected centres.

\section{Conclusion}

This pilot RCT with a nested IDEAL phase 2 study including an innovative intervention shows that this method is feasible and informs the design of a main trial.

\section{Authors' details}

${ }^{1}$ University Hospitals Bristol NHS Foundation Trust, Bristol, UK. ${ }^{2}$ University of Bristol, Bristol, UK. ${ }^{3}$ Plymouth Hospitals NHS Trust, Plymouth, UK. ${ }^{4}$ Imperial

College London, London, UK.

Published: 16 November 2015

doi:10.1186/1745-6215-16-S2-054

Cite this article as: Blazeby et al:: Methods for evaluating innovative surgery: a nested ideal phase 2 study within an external randomised pilot (the ROMIO trial). Trials 2015 16(Suppl 2):O54.
Submit your next manuscript to BioMed Central and take full advantage of:

- Convenient online submission

- Thorough peer review

- No space constraints or color figure charges

- Immediate publication on acceptance

- Inclusion in PubMed, CAS, Scopus and Google Scholar

- Research which is freely available for redistribution

Submit your manuscript at www.biomedcentral.com/submit
() Biomed Central 